\title{
Haemangioma with coagulopathy
}

\author{
Sustained response to prednisone
}

\author{
JOHN EVANS, * A. D. R. BATCHELOR, GORDON STARK, and WILLIAM S. UTTLEY \\ From the Department of Child Life and Health, University of Edinburgh
}

\begin{abstract}
Evans, J., Batchelor, A. D. R., Stark, G., and Uttley, W. S. (1975). Archives of Disease in Childhood, 50, 809. Haemangioma with coagulopathy: sustained response to prednisone. Two cases of giant haemangioma with thrombocytopenia are described. A satisfactory and sustained response to prednisone was achieved in respect of both coagulation abnormalities and tumour size. It is proposed that prednisone is effective by enhancement of thrombosis and reduction of fibrinolysis within the tumour, thus promoting a natural form of resolution. It is suggested that prednisone therapy should be first-choice treatment of complicated haemangiomas.
\end{abstract}

Over 60 cases of haemangioma associated with thrombocytopenia have been reported since the original description of this syndrome by Kasabach and Merritt (1940). The accumulation of isotopelabelled platelets (Kontras et al. 1963) and fibrinogen (Wacksman et al. 1966) within the tumour has confirmed intravascular coagulation as the cause of the associated coagulopathy.

Reduction in tumour size after treatment with corticosteroids in uncomplicated haemangiomata was reported by Fost and Esterly (1968). Sustained improvement of haematological abnormalities in the Kasabach Merritt syndrome treated with steroids alone has not, however, been well documented. Although surgical excision or local radiotherapy have been the most popular methods of treatment in the past (Esterly and Soloman, 1972), Oski and Naiman (1972) recommend prednisone as the preferred initial treatment for the coagulation abnormalities.

We describe below 2 patients who have shown satisfactory and sustained haematological improvement and regression of the haemangioma after treatment with prednisone.

\section{Case reports}

Case 1. An otherwise normal female infant was noted at birth (16 September 1972) to have a very small haemangioma on the anterior abdominal wall to the left of the umbilicus. It slowly increased in size until

Received 14 February 1975.

^Present address: Dept. of Child Health, Welsh National School of Medicine, Cardiff.
6 weeks and then rapidly expanded so that at 3 months when seen by us the haemangioma was a firm, raised lesion about $12 \mathrm{~cm}$ by $9 \mathrm{~cm}$, surrounded by an area of ecchymosis and erythema (Fig. 1). Several large bruises were noted on the lower limbs. Haematological investigations included platelets $9000 / \mathrm{mm}^{3}$, plasma fibrinogen $80 \mathrm{mg} / 100 \mathrm{ml}$, prothrombin time $13 \mathrm{~s}$ (control $14 \mathrm{~s}$ ), partial thromboplastin time $40.5 \mathrm{~s}$ (control $30.5 \mathrm{~s}$ ), serum fibrin/fibrinogen degradation products (FDP) $15 \mu \mathrm{g} / \mathrm{ml}$, Factor V $88 \%$, Factor VIII $100 \%$.

A small biopsy was taken from the periphery of the lesion under cover of a platelet transfusion. Histology showed an uncomplicated capillary haemangioma with occasional large vessels and vasoformative tissue. Prednisone $20 \mathrm{mg}$ daily was given for 5 weeks and tailed off over a 2-week period. Haematological responses are shown in Fig. 2.

Tumour size was reduced by $1 \mathrm{~cm}$ in each diameter at the end of steroid therapy but 4 months later occupied less than one-quarter of its original area. It was superficial and no longer indurated. The lesion has subsequently regressed further and is now represented only by a superficial telangiectasia.

Case 2. This term female infant (born 29 October 1973) was noted at birth to have a large haemangioma involving the whole of the right anterior chest, right lateral chest, and lower part of the anterior left chest (Fig. 3). There was no clinical evidence of bleeding or cardiac decompensation. At 20 hours the platelet count was $1200 / \mathrm{mm}^{3}$; at 2 days platelets were $9000 / \mathrm{mm}^{3}$, plasma fibrinogen $210 \mathrm{mg} / 100 \mathrm{ml}$, serum FDP $70 \mu \mathrm{g} / \mathrm{ml}$, prothrombin time $15.5 \mathrm{~s}$ (control $14 \mathrm{~s}$ ), partial thromboplastin time $35 \mathrm{~s}$ (control $40 \mathrm{~s}$ ).

A platelet transfusion was given and treatment started with prednisone $20 \mathrm{mg}$ daily. Details of 


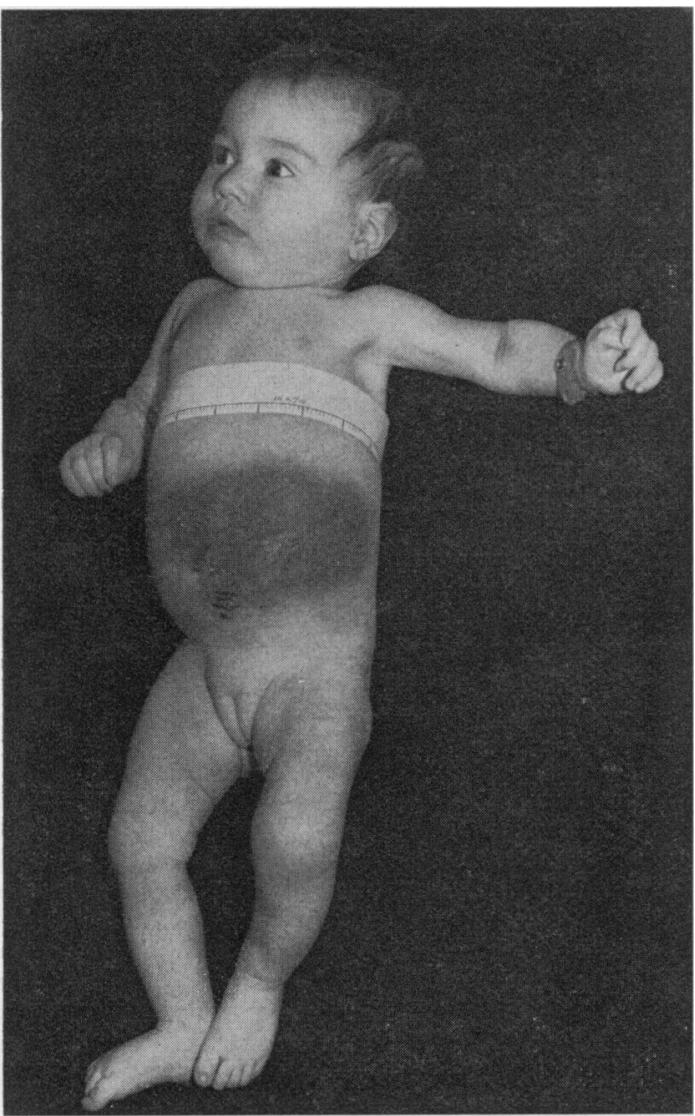

FIG. 1.-Case 1. Extensive haemangioma of abdominal wall before treatment.

therapy and haematological changes are shown in Fig. 4. Serum FDP concentrations were within normal limits after 3 days. After 4 weeks of treatment the haemangioma appeared paler and softer and its surface had a puckered appearance. Subsequently there was a progressive reduction in tumour size and at 8 months little more than blue mottling could be seen over the anterior chest wall.

\section{Discussion}

The natural history of the majority of uncomplicated 'strawberry' naevi of this type is one of spontaneous remission and hence they are best managed expectantly. Active treatment is indicated in haemangiomata complicated by coagulation abnormalities, excessive limb growth, cardiac failure, or gross cosmetic handicap. Prednisone and other corticosteroids are known to reduce tumour size (Fost and Esterly, 1968) and the temporal relations strongly suggest that this has also
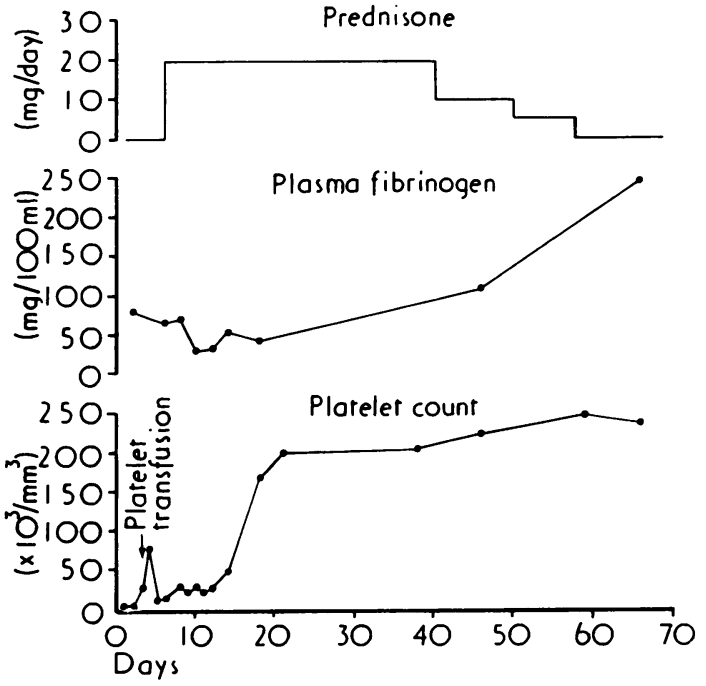

Fig. 2.-Case 1. Haematological and coagulation responses during treatment with prednisone.

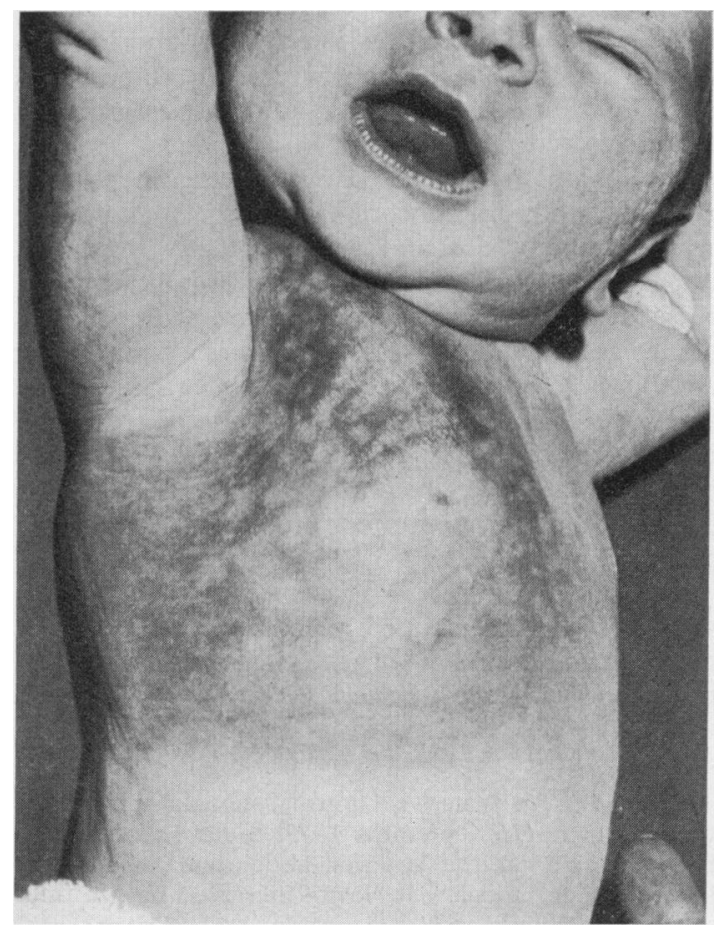

FIG. 3.-Case 2. Showing extent of haemangioma over right chest at age 2 days. 

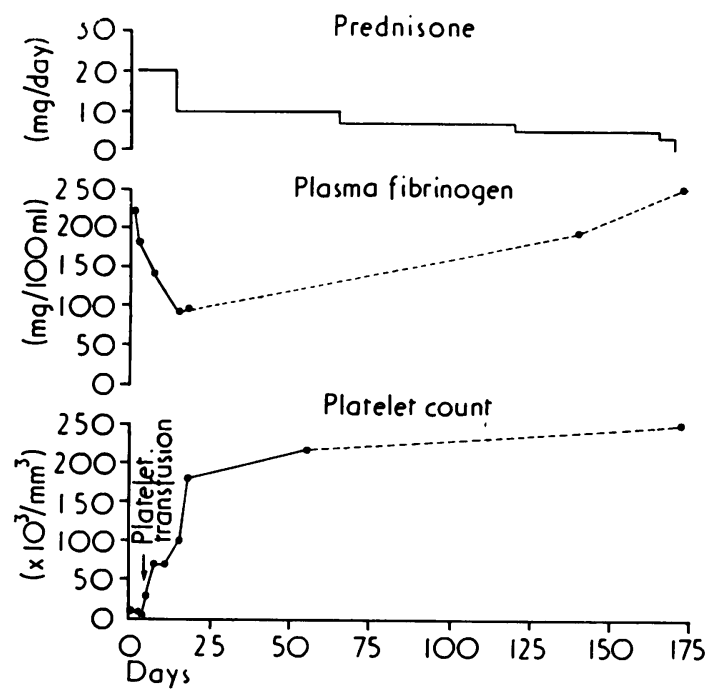

FIg. 4.-Case 2. Haematological and coagulation responses during treatment with prednisone.

occurred in our cases. Of greater interest, however, is the early and sustained haematological response which occurred before any visual change in the tumour. Previously reported cases have either relapsed after withdrawal of steroids (e.g. the 13year-old boy of Katz and Askin, 1968, with multiple haemangiomata), or received additional treatment such as irradiation and/or surgery (16 cases reviewed by Katz and Askin, 1968; Schneider and Lascari 1968; Odievre et al., 1971).

It is uncertain whether in these cases the effect of steroid therapy is primarily on the haemangioma itself or on the associated coagulation defect. Corticosteroids have been shown by Zweifach, Shorr, and Black (1953) to have a direct influence on vascular tone and to sensitize vessels to the effect of vasoconstrictor amines. Thus resolution of the haemangioma may follow a reduction in its blood supply with a consequent reduction in local intravascular coagulation.

More attractive, however, is the hypothesis that the steroid enhances thrombosis and inhibits subsequent fibrinolysis within the vascular channels, thus leading to their obliteration. The effect of corticosteroids on coagulation and fibrinolytic mechanisms is complex. Ozsoylu, Strauss, and Diamond (1962) showed steroid therapy to be associated with increased activity of antihaemophilic globulin and a reduction in partial thromboplastin time. Hypercoagulability is a recognized problem in patients receiving treatment with steroids and thromboembolic complications occurring in such patients were reviewed by Cosgriff (1951). Although steroids may enhance physiological fibrinolysis in vivo (Fearnley and Bunim, 1951) 'pathological' fibrinolysis was inhibited in patients with hepatic cirrhosis (Kwaan and McFadzean, 1956), and Isacson (1971) showed that prednisone diminished the content of plasminogen activator in the walls of superficial veins. In support of the latter hypothesis our own results show a fall in the plasma fibrinogen concentrations following immediately upon the initiation of treatment, and a rather slow recovery therafter. Furthermore, the raised concentrations of serum FDP in Case 2 rapidly returned to normal. The temporal relations between haematological and haemangioma responses do not suggest that the primary effect of treatment is upon haemangioma. They infer that the normal resolution of such haemangiomata may be dependent upon naturally occurring thrombosis within the vascular channels and that such spontaneous regression may be accelerated by prednisone therapy. If this is indeed the mechanism of response then investigation of the use of more potent inhibitors of fibrinolysis, such as $\epsilon$-amino caproic acid, might be of particular value.

Surgical extirpation or irradiation of haemangiomata as recommended previously will frequently be successful in resolving associated coagulation abnormalities. Nevertheless these treatments commonly leave residual scarring, and in the case of irradiation local necrosis with haemorrhage, and even later malignancy may be additional complications. Aggressive therapy with prednisone obviates these sequelae. It appears to have the virtue of precipitating a spontaneous type of resolution and should be considered as a first choice in the treatment of complicated haemangiomata.

We thank Mr. D. A. Franklin, photographer, Bangour General Hospital, and Mr. S. Donald, photographer, Royal Hospital for Sick Children, Edinburgh, for help with figures, and Dr. J. D. Cash, South-East Scotland Blood Transfusion Service, Royal Infirmary, for help with coagulation assays.

\section{REFERENCES}

Cosgriff, S. W. (1951). Thromboembolic complications associated with ACTH and cortisone therapy. Fournal of the American Medical Association, 147, 924.

Esterly, N. B., and Solomon, L. M. (1972). Neonatal dermatology. III. Pigmentary lesions and hemangiomas. fournal of Pediatrics, 81, 1003.

Fearnley, G. R., and Bunin, J. J. (1951). The effect of ACTH on erythrocyte sedimentation rate and plasma-fibrinogen and serum-protein levels in normal persons. Lancet, $2,1113$.

Fost, N. C., and Esterly, N. B. (1968). Successful treatment of juvenile hemangiomas with prednisone. Fournal of Pediatrics, 72, 351. 
Isacson, S. (1971). Low fibrinolytic activity of blood and vein walls in venous thrombosis. Scandinavian fournal of Haematology, Suppl. 16, 21.

Kasabach, H. H., and Merritt, K. K. (1940). Capillary haemangioma with extensive purpura-report of a case. American Fournal of Diseases of Children, 59, 1063.

Katz, H. P., and Askin, J. (1968). Multiple haemangiomata with thrombopenia. American Fournal of Diseases of Children, 115, 351.

Kontras, S. B., Green, O. C., King, L., and Duran, R. J. (1963). Giant hemangioma with thrombocytopenia; case report with survival and sequestration studies of platelets labelled with chromium 51. American fournal of Diseases of Children, 105, 188.

Kwaan, H. C., and McFadzean, A. J. S. (1956). The inhibition of clot lysis by corticotrophin. Lancet, 1, 136.

Odievre, M., Hamaza, M., Joannides, Z., and Alagille, D. (1971). Angiome du nourrisson: effet favourable de l'hydrocortisone intraveineuse. Archives Françaises de Pédiatrie, 28, 443.
Oski, F. A., and Naiman, J. L. (1972). Hematologic Problems in the Newborn, Vol. IV, Major Problems in Clinical Pediatrics, 2nd ed., p. $304 . \quad$ Saunders, Philadelphia.

Ozsoylu, S., Strauss, H. S., and Diamond, L. K. (1962). Effects of corticosteroids on coagulation of the blood. Nature, 195, 1214

Schneider, H. J., and Lascari, A. D. (1968). Consumption coagulopathy in an infant with Kasabach-Merritt syndrome. Helvetica Paediatrica Acta, 23, 674.

Wacksman, S. J., Flessa, H. C., Glueck, H. I., and Will, J. (1966). Coagulation defects and giant cavernous hemangioma. American Fournal of Diseases of Children, 111, 71.

Zweifach, B. W., Shorr, E., and Black, M. M. (1953). The influence of the adrenal cortex on behaviour of terminal vascular bed. Annals of the New York Academy of Sciences, 56, 626.

Correspondence to Dr. W. S. Uttley, Department of Child Life and Health, University of Edinburgh, 17 Hatton Place, Edinburgh EH9 1UW.

The following articles will appear in future issues of this journal:

Looking back: Phototherapy. R. H. Dobbs and R. J. Cremer.

Generalized seborrhoeic dermatitis: clinical and therapeutic data of 25 patients. M. Messaritakis, C. Kattamis, C. Karabula, and N. Matsaniotis.

Congenital H-type tracheo-oesophageal fistula. B. Sundar, E. J. Guiney, and B. O'Donnell.

Lamellation of the diploe in skulls of patients with sickle cell anaemia. A. O. Williams, S. B. Lagundoye, and C. L. Johnson.

Sick sinus syndrome: symptomatic cases in children. D. J. Radford and T. Izukawa.

Hypernatraemia as a cause of intracranial haemorrhage. $N$. R. C. Roberton and P. Howat.

Secretion of prednisolone into breast milk. S. A. McKenzie, J. A. Selley, and J. E. Agnew.

Sex-related incidence in proteus infection of the urinary tract in childhood. $S$. R. Saxena and D. C. J. Bassett. 